\title{
A Summary of DOD-Sponsored Research Performed at NASA Langley's Impact Dynamics Research Facility
}

\author{
Karen E. Jackson, Richard L. Boitnott, and Edwin L. Fasanella \\ Karen.E.Jackson-1@nasa.gov, Richard.L.Boitnott@nasa.gov, Edwin.L.Fasanella@nasa.gov \\ U.S. Army Research Laboratory, Vehicle Technology Directorate \\ Hampton, VA
}

\author{
Lisa E. Jones and Karen H. Lyle \\ Lisa.E.Jones@nasa.gov, Karen.H.Lyle@nasa.gov \\ Structural Dynamics Branch \\ NASA Langley Research Center \\ Hampton, VA
}

\begin{abstract}
The Impact Dynamics Research Facility (IDRF) is a 240-ft.-high gantry structure located at NASA Langley Research Center in Hampton, Virginia. The IDRF was originally built in the early 1960's for use as a Lunar Landing Research Facility. As such, the facility was configured to simulate the reduced gravitational environment of the Moon, allowing the Apollo astronauts to practice lunar landings under realistic conditions. In 1985, the IDRF was designated a National Historic Landmark based on its significant contributions to the Apollo Moon Landing Program. In the early 1970's the facility was converted into its current configuration as a full-scale crash test facility for light aircraft and rotorcraft. Since that time, the IDRF has been used to perform a wide variety of impact tests on full-scale aircraft, airframe components, and space vehicles in support of the General Aviation (GA) aircraft industry, the U.S. Department of Defense (DOD), the rotorcraft industry, and the NASA Space program. The objectives of this paper are twofold: to describe the IDRF facility and its unique capabilities for conducting structural impact testing, and to summarize the impact tests performed at the IDRF in support of the DOD. These tests cover a time period of roughly $21 / 2$ decades, beginning in 1975 with the full-scale crash test of a CH-47 Chinook helicopter, and ending in 1999 with the external fuel system qualification test of a UH-60 Black Hawk helicopter. NASA officially closed the IDRF in September 2003; consequently, it is important to document the past contributions made in improved human survivability and impact tolerance through DOD-sponsored research performed at the IDRF.
\end{abstract}

\section{INTRODUCTION}

The Impact Dynamics Research Facility was originally built as a Lunar Landing Research Facility (LLRF) that became operational in 1965. The steel A-frame gantry structure is $240-\mathrm{ft}$. high, $400-\mathrm{ft}$. long, and $265-\mathrm{ft}$. wide at the base. The LLRF was used to train Apollo astronauts to fly in a simulated lunar environment during the last 150ft. of descent to the surface of the moon. The astronauts performed these tests in a Lunar Excursion Module Simulator (LEMS) that was tethered to the gantry. The gantry suspension system was designed to support 5/6th of the total weight of the LEMS, thus simulating the reduced (1/6th) gravitational field of the moon. The surface beneath the gantry was modified to resemble the lunar landscape and many of the tests were performed at night to mimic the actual lighting conditions during the moon landing. Photographs of the LEMS descending onto the simulated lunar surface at the LLRF are shown in Figure 1. In 1985, the facility was designated a National Historic Landmark based on its significant contributions to the

Presented at the American Helicopter Society 60th Annual Forum, Baltimore, MD, June 7-10, 2004. This paper is a work of the U.S. Government and is, therefore, in the public domain.
Apollo Moon Landing Program. References 1 and 2 describe the operational features of the LLRF and the results of flight tests performed using the facility.

At the end of the Apollo program, the LLRF was converted into a full-scale crash test facility for investigating the crashworthiness of General Aviation (GA) aircraft and was designated the Impact Dynamics Research Facility (IDRF). The purpose and benefit of full-scale crash testing, as defined in Reference 3 , is "to obtain definitive data on the structural response of aircraft and on the loads transmitted to the occupants during a crash impact. These data can be used for correlation with results of analytical predictive methods. Full-scale aircraft crash tests can also be used to evaluate crashworthy design concepts both for the aircraft structure and for seat and restraint systems." One of the important features of this facility is the ability to perform full-scale crash tests of light aircraft and rotorcraft under free-flight conditions; and, at the same time, to control the impact attitude and velocity of the test article upon impact. Also, full-scale crash tests can be performed for a wide range of combined forward and vertical velocity conditions. Most GA aircraft tests are performed with a higher forward velocity and a lower vertical velocity. For example, the 1994 crash test of the Lear Fan 2100 aircraft was performed at 82-fps 
forward and 31-fps vertical velocity. Conversely, helicopters are typically tested with a higher vertical and lower forward velocity. For example, the 1999 crash test of a Sikorsky prototype helicopter was performed at 31.5fps forward and 38-fps vertical velocity. Currently, the IDRF is limited to test articles weighing $30,000 \mathrm{lb}$. or less.

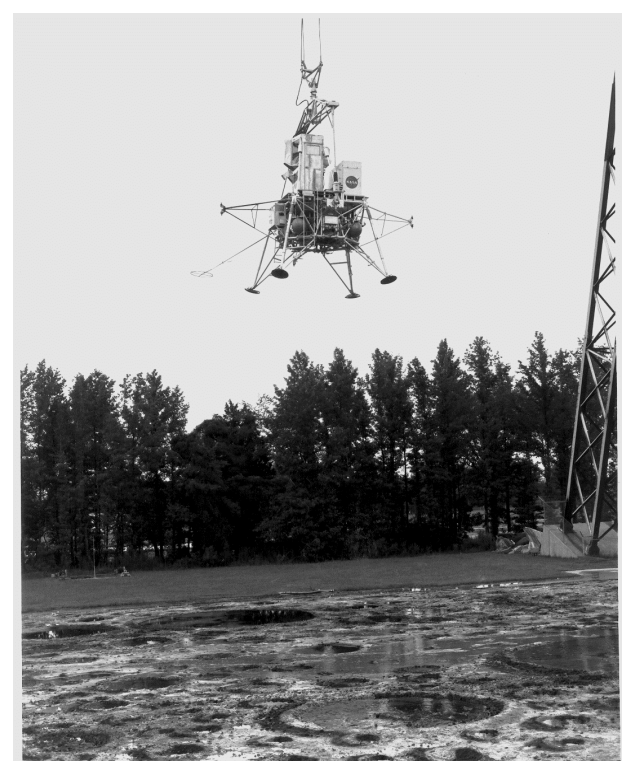

(a) LEMS descending to the simulated lunar surface.

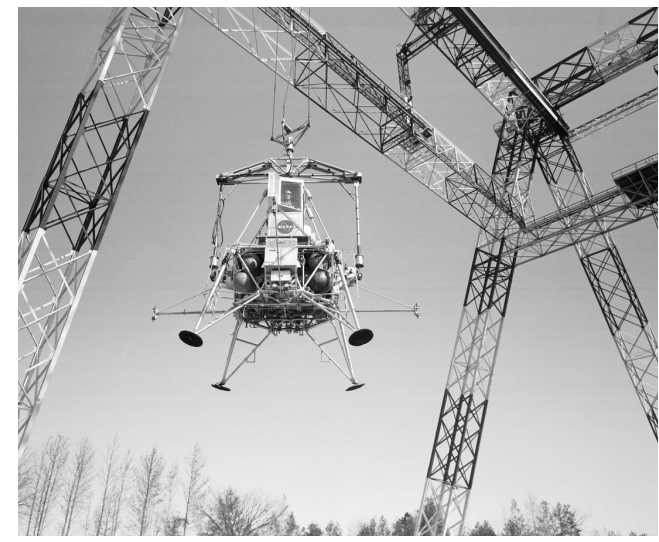

(b) LEMS tethered from the gantry.

Figure 1. Photographs of the LEMS descending to the simulated moon surface.

Since the first full-scale crash test was performed in February of 1974, the IDRF has been used to conduct: 41 full-scale crash tests of GA aircraft including landmark studies to establish baseline crash performance data for metal and composite aircraft, 11 full-scale crash tests of helicopters including crash qualification tests of the Bell and Sikorsky Advanced Composite Airframe Program (ACAP) helicopters, 48 Wire Strike Protection System (WSPS) qualification tests of Army helicopters, 3 vertical drop tests of Boeing 707 transport aircraft fuselage sections, and 60 to 70 drop tests of the F-111 crew escape module. In addition, the facility has been used to perform numerous component tests in support of the Mars Sample Return Earth Entry Vehicle program, as well as a number of other unique experiments including a tethered-hover test of the XFV12A, a vertical drop test of a $\mathrm{CH} 47$ helicopter fuselage section with a container for artillery-fired projectiles, and several drop tests of an energy-absorbing pallet for deployment of a remotecontrolled vehicle. A general history of the crash test programs conducted at the IDRF is documented in Reference 4. The focus of this paper is to highlight the significant contributions made in improved human survivability and crashworthy structural design through DOD-sponsored testing performed at the IDRF.

\section{DESCRIPTION OF THE IDRF}

A photograph of the IDRF is shown in Figure 2(a). The gantry structure is oriented in an east-west direction and is composed of truss elements arranged in three sets of inclined legs to give vertical and lateral support. An additional set of inclined legs located at the east end of the gantry provides longitudinal support. The legs are inclined at an angle of 25-degrees from vertical and they are $265 \mathrm{ft}$. apart at the ground level. An enclosed elevator and a stairway provide access to the overhead work platforms. A movable bridge spans the gantry at the 217-ft. level and runs the length of the gantry. In 1981, a 70-ft. vertical drop tower, designated the Vertical Test Apparatus, was added beneath the northwest leg of the gantry, shown in Figure 2(b), for the purpose of conducting vertical drop tests of Boeing 707 fuselage sections. These tests were conducted in support of a full-scale crash test of a remotely-piloted Boeing 720 transport aircraft that was conducted at Edwards Air Force Base in 1984 (see Reference 4).

Full-scale crash tests are performed at the IDRF using a pendulum swing technique, as illustrated schematically in Figure 3. Two pivot-point platforms are located at the top of the west end of the gantry, one on the north and one on the south side. The platforms support two winches used for controlling the length of the swing cables. A pullback platform is located on the underside of the movable bridge that traverses the 400-ft. length of the gantry in an east-west direction. This platform also supports a winch for lifting the test aircraft using the pullback cable. The swing and pullback cables connect to the aircraft swing and pullback harnesses. The harnesses are designed specifically for the aircraft configuration being tested. The cable lengths of the aircraft swing and pullback harnesses can be adjusted to provide a wide range of roll, pitch, or yaw attitudes at impact. The harness cables are typically mounted to hard points on the airframe. Ideally these hard points are located such that a line connecting them passes through the center-of-gravity of the test article. During the test, the aircraft is raised through the pullback cable to the desired drop height. Following a countdown, the pullback cable is pyrotechnically cut, releasing the aircraft to swing towards the impact surface. Just prior to impact, the swing cables are pyrotechnically separated from the aircraft such that it is completely unrestrained during the impact. More detailed descriptions of the IDRF fullscale crash test procedures are provided in References 3 and 5. 


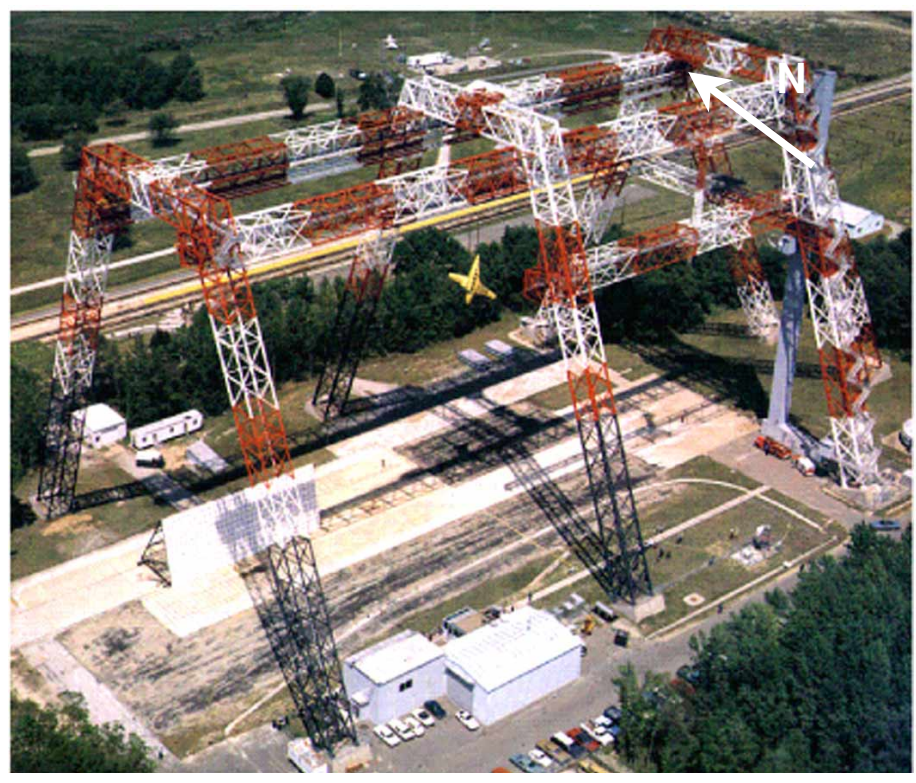

(a) IDRF gantry.

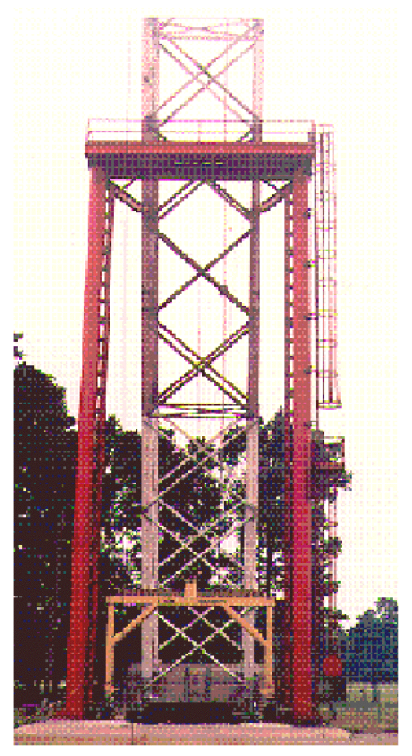

(b) Vertical drop tower.

Figure 2. Photograph of the IDRF located at NASA Langley Research Center.

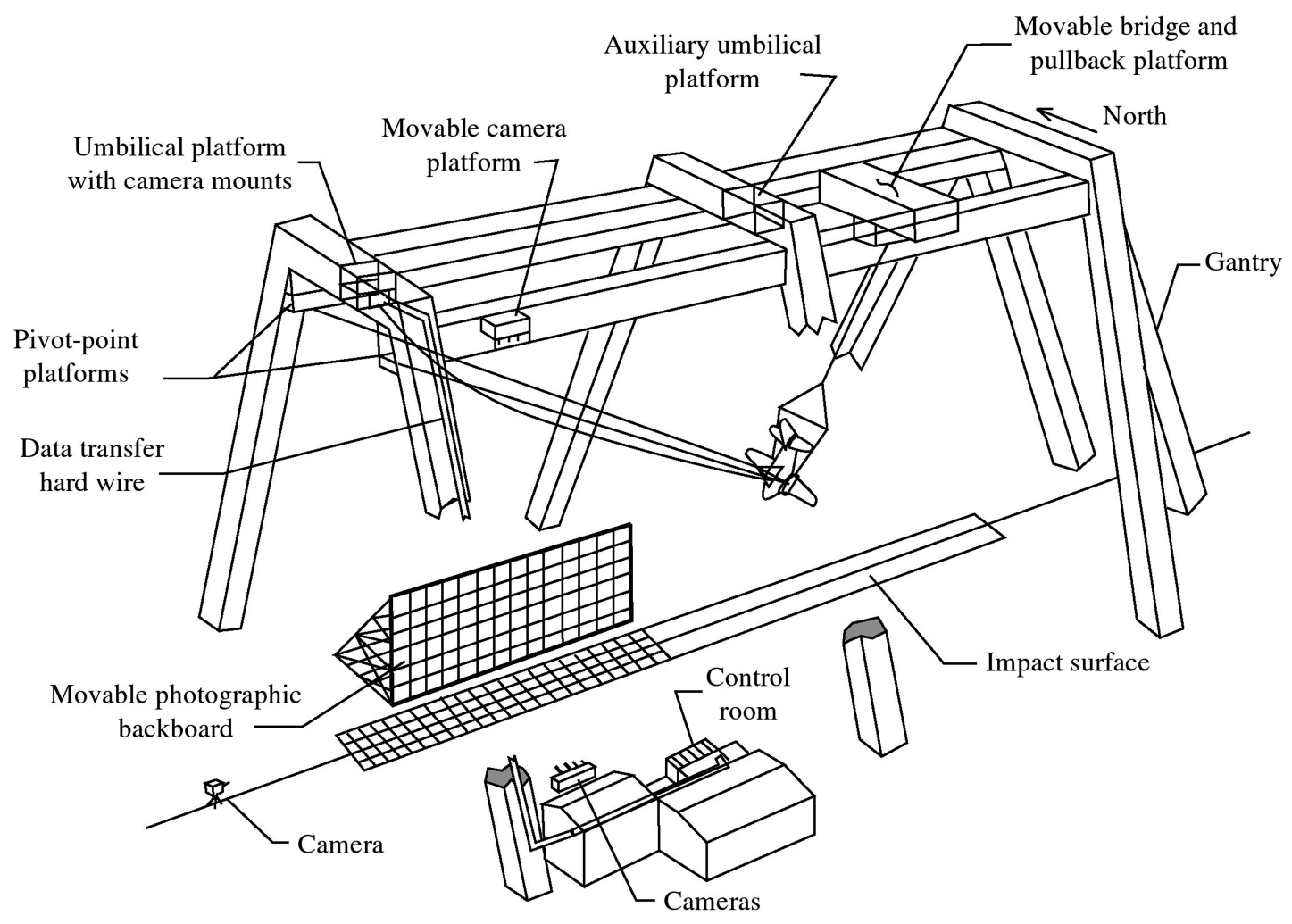

Figure 3. Schematic drawing of the IDRF illustrating full-scale crash test procedures.

\section{MILITARY CRASH TEST PROGRAMS: 1975 - 1999}

The crash test programs that have been conducted at the IDRF in support of the DOD during the period from 1975 through 1999 are shown in the timeline of Figure 4. Each of these test programs will be described briefly in the following sections of the paper. These descriptions are not intended to provide comprehensive information and, where possible, references are given to enable the reader to find additional information. 


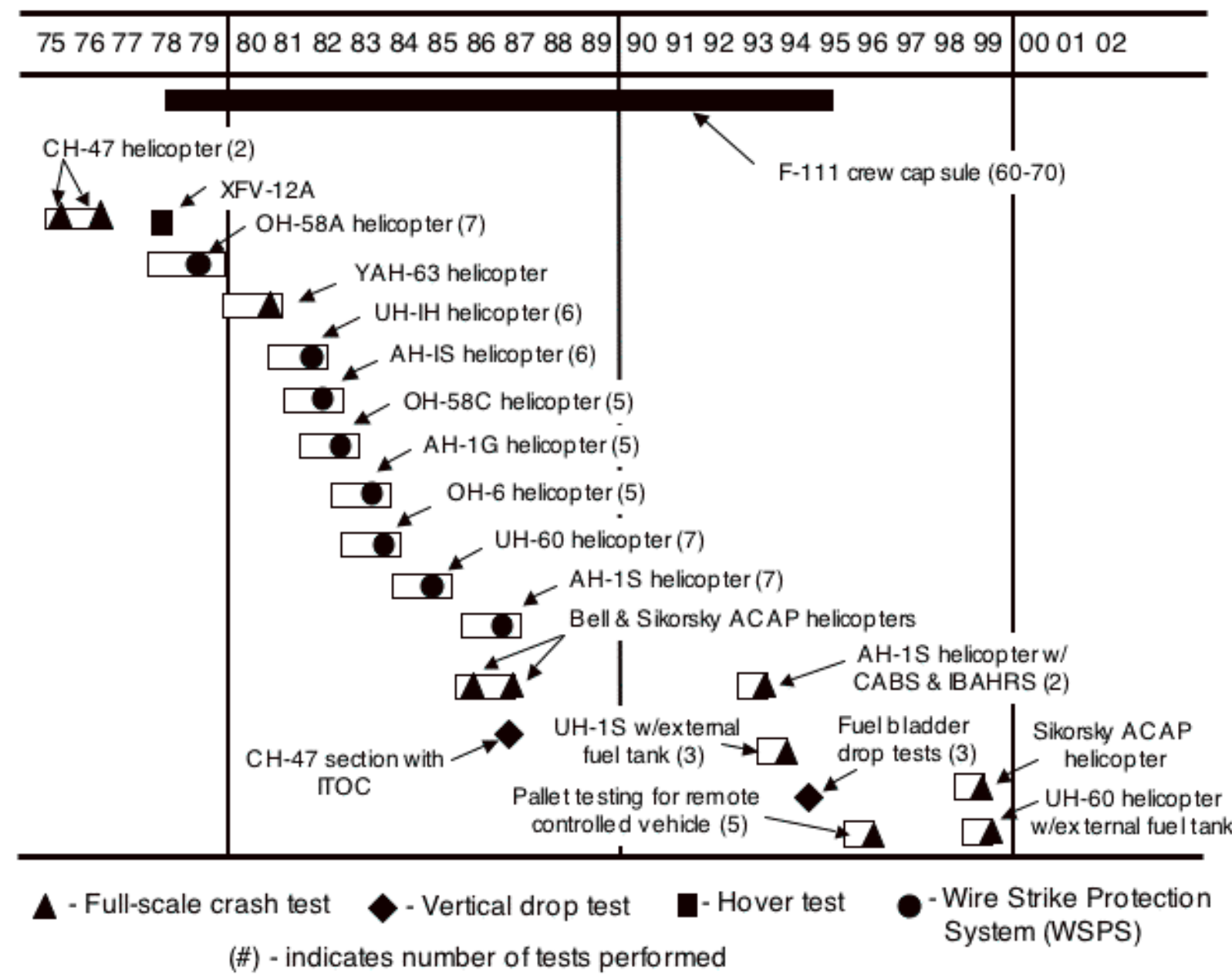

Figure 4. Time line of DOD-sponsored test programs performed at the IDRF.

\section{Crash Testing of the CH-47 Chinook Helicopter}

In 1975 and 1976, two full-scale crash tests of the CH-47 "Chinook" helicopter were performed in support of the U.S. Army Aviation Applied Technology Directorate (AATD) located at Ft. Eustis, VA. The CH-47 helicopter is a heavy lift, troop, and equipment transport helicopter and a pre-test photograph is shown in Figure 5. The objectives of the tests were to evaluate the load-limiting performance of the seats, the structural response of the airframe, and the integrity of the cargo restraint systems $[6,7]$. A series of photographs showing the sequence of events during the crash test of the $\mathrm{CH}-47$ helicopter is shown in Figure 6. Data acquired from these initial helicopter crash tests were used to correlate with KRASH [8] computer models. Also, results from the tests highlighted several potential structural and post-crash fire hazards.

\section{Tethered-Hover Test of the XFV-12A}

In early 1978, a team of NASA, Navy, and North American Rockwell personnel performed tethered-hover tests of the full-scale XFV-12A at the IDRF. A photograph of the $\mathrm{XFV}-12 \mathrm{~A}$ during a tethered hover test is shown in Figure 7. Some fairly extensive modifications were made to the IDRF to allow tethered-hover tests for powered vertical take-off and landing aircraft. During six months of testing of the XFV-12A, major deficiencies were apparent in hovering flight, including marginal thrust augmentation and relatively poor handling qualities. The findings from this test program helped influence the Navy's decision to cancel the XFV-12A program [9].

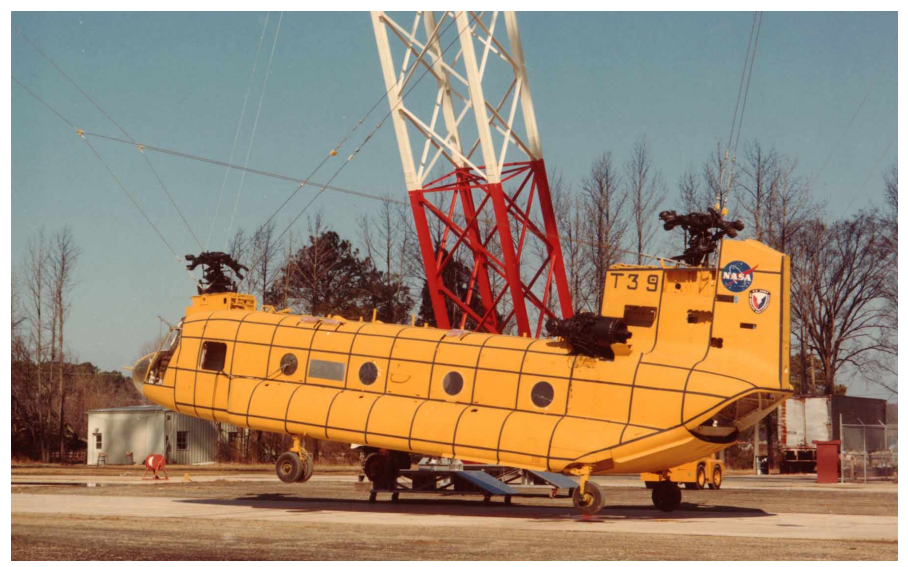

Figure 5. Pre-test photograph of the full-scale crash test of a CH-47 helicopter. 

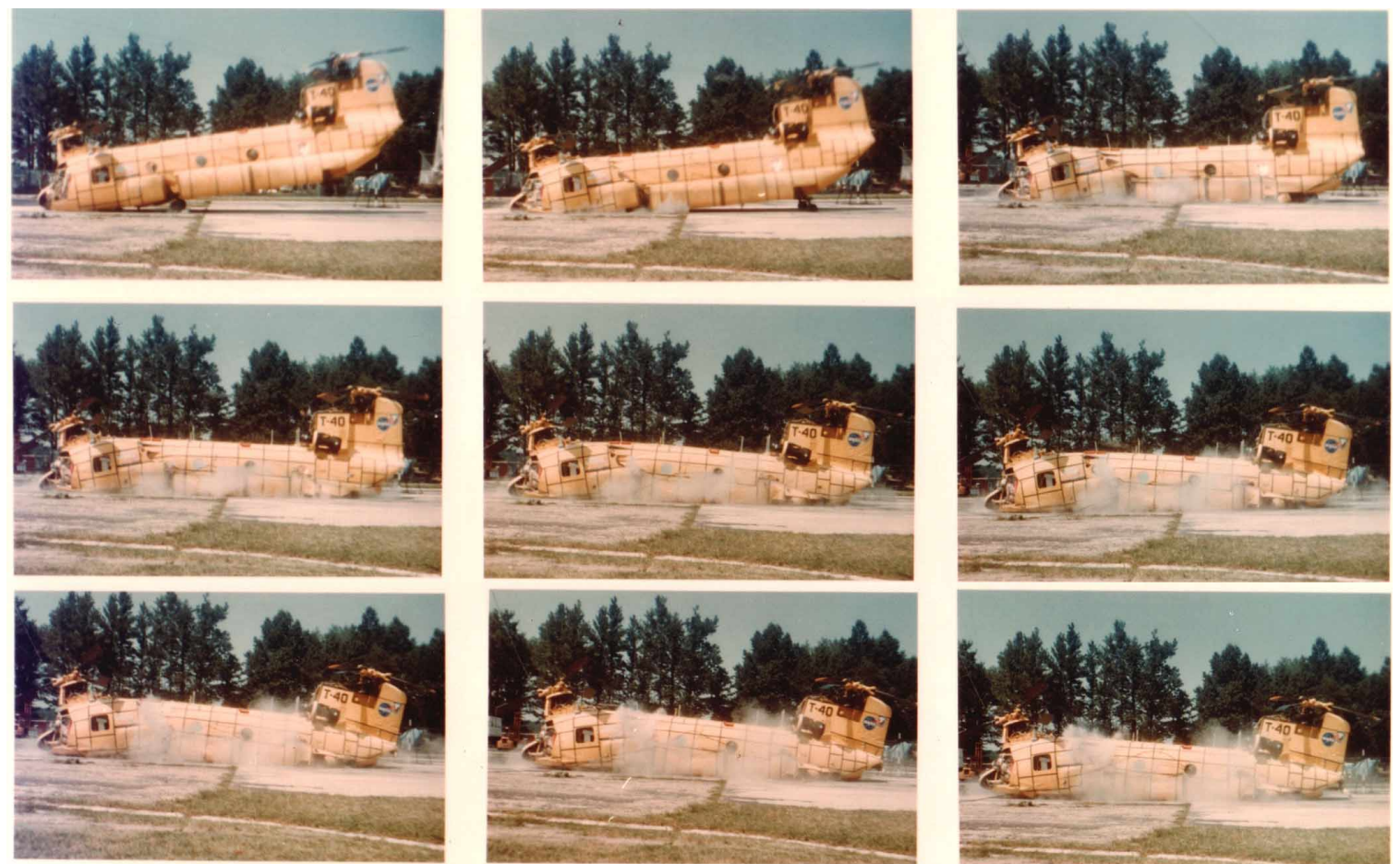

Figure 6. Series of photographs showing the deformation of the $\mathrm{CH}-47$ helicopter during crash testing.

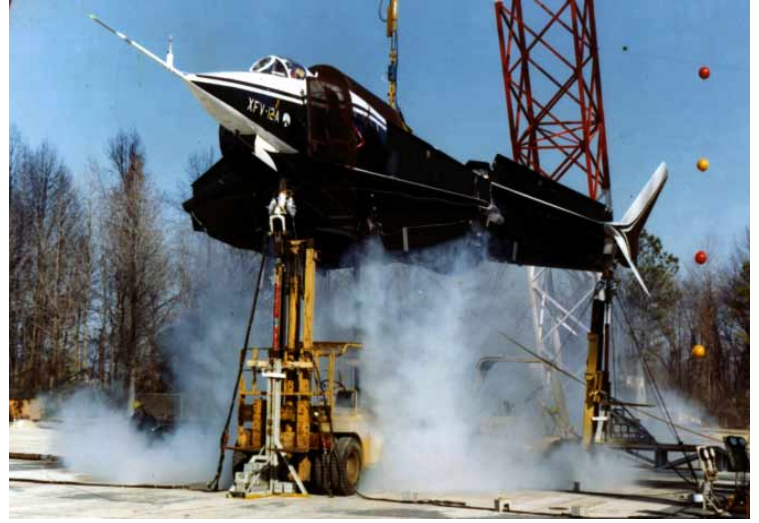

Figure 7. Tethered-hover test of the XFV-12A in 1978.

\section{Wire Strike Protection System (WSPS) Testing}

The U.S. Army AATD sponsored a series of Wire Strike Protection System (WSPS) qualification tests on different Army helicopters [10-12]. Based on helicopter accident data, it was found that many crashes occurred during napof-the-earth flight when pilots accidentally flew the helicopters into utility cables. A passive system was designed to minimize this problem. Two blade-type devices, fabricated of hardened steel, are attached to the top and bottom of the helicopter fuselage. During a wire strike, the cables are intended to slide either up or down the front of the helicopter and get caught in the blade-type devise. The cable is then notched and severed. Qualification tests were performed at the IDRF to verify the passive WSPS design for all Army helicopters. The tests were performed by attaching a 3/8-in.-diameter steel cable to tele- phone poles located on opposite sides of the gantry. The helicopter was suspended from the gantry, pulled back into the release position, and then released to swing into the cable. The vertical elevation of the helicopter was adjusted to test different cutter locations, such as the roof or belly cutters. A photograph showing a WSPS test of an AH-1 Cobra helicopter is depicted in Figure 8. The passive WSPS concept, as validated during tests at the IDRF, has been highly effective in protecting helicopters against mishaps caused by wire strikes. Fewer accidents, injuries, and fatalities have resulted in Army helicopters that are equipped with WSPS. Currently the passive WSPS systems are installed fleet-wide on all military helicopters and are optional equipment on many commercial helicopters.

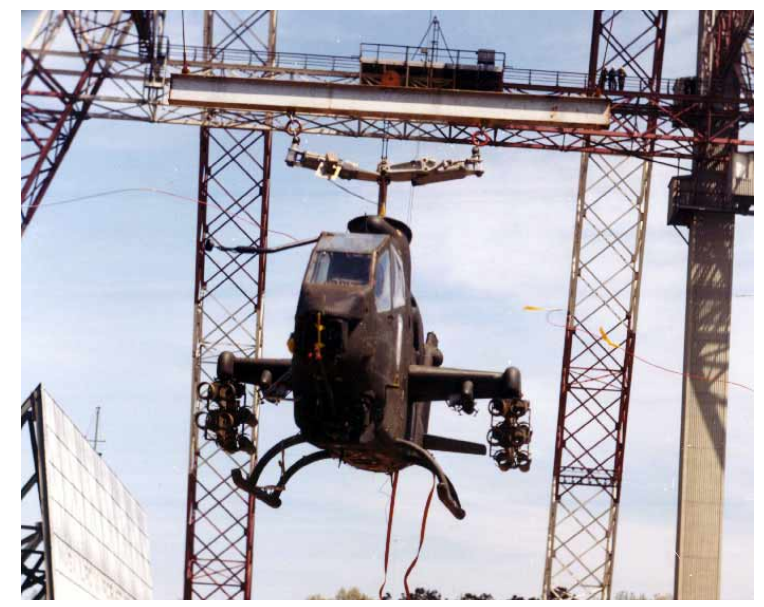

Figure 8. Photograph of a WSPS test performed on an AH-1 Cobra helicopter. 


\section{Full-Scale Crash Test of the Bell YAH-63 Helicopter} In 1981, a full-scale crash test of the YAH-63 prototype helicopter was conducted at the IDRF. This helicopter was designed and manufactured by Bell Helicopter Textron as its bid in the competition for the Army's Advanced Attack Helicopter (AAH) program. The crash test was performed to evaluate the energy-absorbing and loadlimiting features of the airframe, landing gear, and seats. A pre-test photograph of the YAH-63 helicopter in the impact position is shown in Figure 9(a). A photograph of the YAH-63 during the crash test is shown in Figure 9(b). The Bell airframe did not win the award, which went to the Hughes Helicopter (now Boeing) AH-64 Apache.

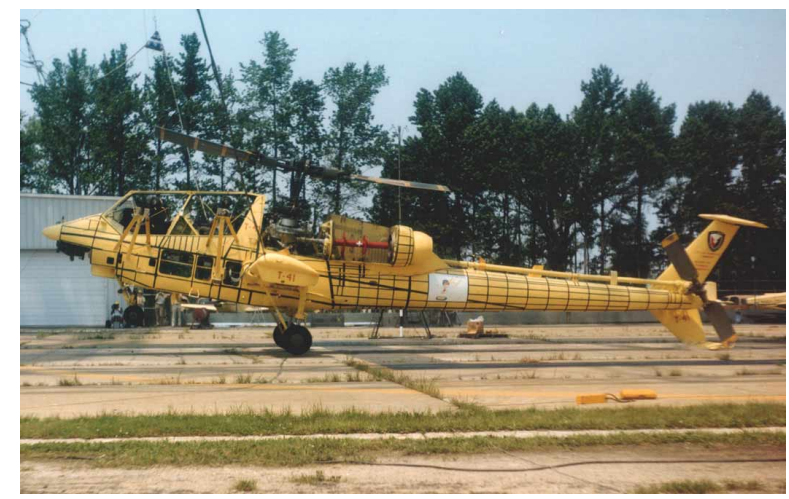

(a) Pre-test photograph.

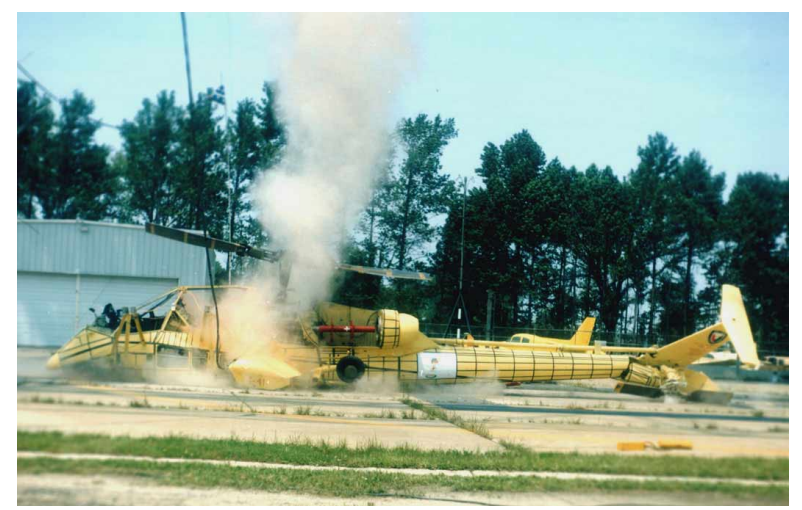

(b) Photograph during impact.

Figure 9. Photographs of the Bell YAH-63 helicopter.

\section{Full-Scale Crash Tests of the ACAP Helicopters}

Full-scale crash qualification tests were performed at the IDRF on the Bell and Sikorsky Advanced Composite Airframe Program (ACAP) helicopters in 1987 [13-15]. The purpose of the Army-sponsored ACAP was to demonstrate the potential of advanced composite materials to save weight and cost in airframe structures while achieving systems compatibility and meeting military requirements for vulnerability reduction, reliability, maintainability, and survivability. In 1981, the U.S. Army awarded separate contracts to Bell Helicopter Textron and Sikorsky Aircraft Company to develop, manufacture, and test helicopters constructed primarily of advanced composite materials. Each company manufactured three airframes that were tested under a variety of static and dynamic conditions to demonstrate namic conditions to demonstrate compliance with the program objectives. In addition, one helicopter airframe from each company was equipped to become a flying prototype. Crash tests of the Bell and Sikorsky ACAP static test articles were conducted in 1987 at the IDRF in support of the U.S. Army AATD to demonstrate their impact performance and to verify compliance with crash requirements. Pre- and post-test photographs of the full-scale crash tests are shown in Figure 10. The Bell ACAP helicopter impacted with a combined 42-fps vertical and 27-fps forward velocity, while the Sikorsky ACAP helicopter impacted at 39-fps vertical velocity. These tests demonstrated the successful application of composite materials to save weight and maintenance costs in rotorcraft design, while also achieving improved crash performance.

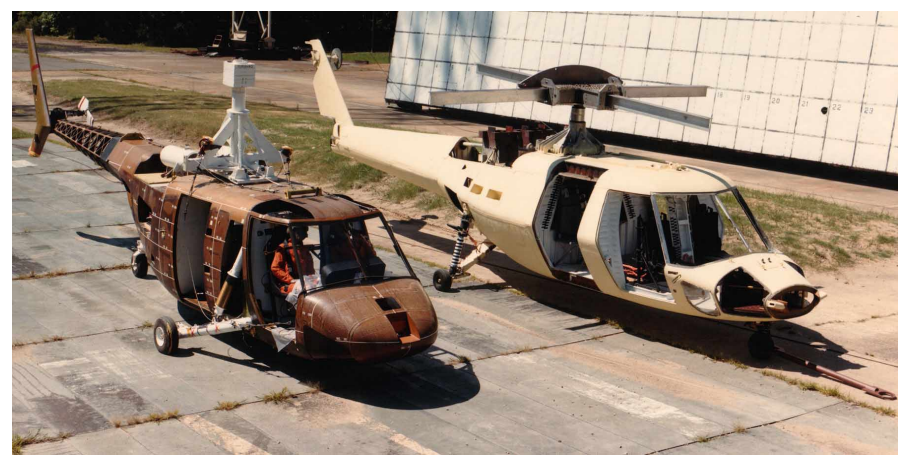

(a) Pre-test photograph of the Bell and Sikorsky ACAP helicopters.

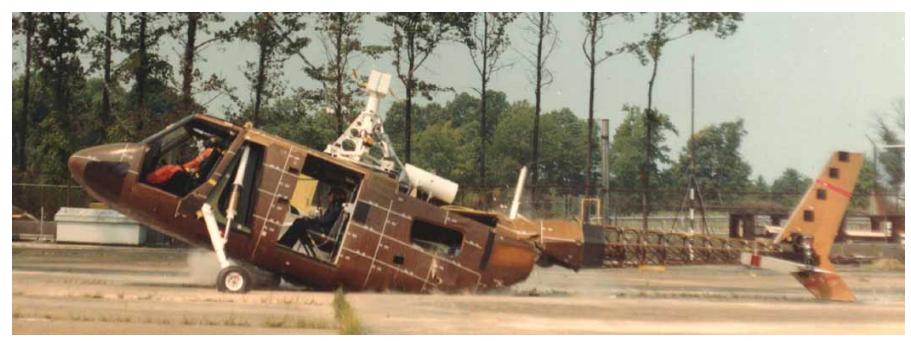

(b) Photograph of the Bell ACAP helicopter during full-scale crash test.

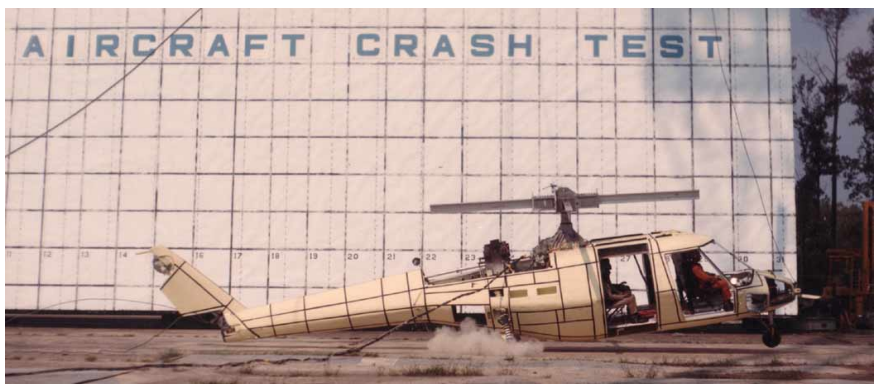

(c) Photograph of the Sikorsky ACAP helicopter during fullscale crash test.

Figure 10. Photographs of the Bell and Sikorsky ACAP helicopters, before and during full-scale crash tests performed at the IDRF. 


\section{Drop Testing of the Interim Transportation Overpack} Container (ITOC)

In the late 1980's, the U.S. Army Armament Research, Development and Engineering Center (ARDEC) located at Picatinny Arsenal in New Jersey was developing an Interim Transportation Overpack Container (ITOC) to house artillery-fired projectiles for peacetime movement by helicopters. The ITOC is required to retain and limit the load to the projectiles during a high velocity impact and subsequent fuel fire that might occur in association with a helicopter crash. During the development of the ITOC system, drop tests of $1 / 3$ scale models were conducted by ARDEC to aid in the development of the prototype. Additional full-scale drop tests were conducted at the IDRF on prototype designs in support of the ARDEC program. The purpose of the drop tests was to investigate the ITOC's capability to maintain structural integrity under high g-loads resulting from a high velocity impact of a CH-47 helicopter section containing the ITOC. Vertical drop tests were performed at the IDRF of $\mathrm{CH}-47$ helicopter fuselage sections containing the ITOC from heights of 190- to 195-ft. resulting in impact velocities of 110- to 112-fps. Pre- and post-test photographs of the Ch-47 helicopter section containing the ITOC are shown in Figure 11. In addition to performing the impact tests and data evaluation, a finite element model of the ITOC was developed to correlate analytical predictions of the response of the ITOC and helicopter assembly with test data [16]. The results of this test program proved that the ITOC would protect artillery-fired projectiles in the event of an extremely severe crash of the helicopter that was transporting them.

\section{Full-Scale Crash Testing of a AH-1S Cobra Helicopter with CABS and IBAHRS}

In the early 1990's, the U.S. Army was actively supporting the development of crew restraint technologies based on studies showing that a high percentage of crash injuries resulted from occupants striking interior cockpit structures. In 1993, two full-scale crash tests of an AH1S Cobra helicopter were conducted at the IDRF to demonstrate the performance of active crew restraint systems under realistic crash conditions. In particular, the tests, sponsored by the U.S. Army AATD, were performed to evaluate the Inflatable Body and Head Restraint System (IBAHRS) and the Cockpit AirBag System (CABS) [17]. IBAHRS is an active restraint system that consists of two sealed airbags integrated into a standard five-point restraint harness, with gas generators, a crash sensor, and airframe specific modifications. The IBAHRS airbags are attached to the underside of the shoulder straps to restrain the torso of the occupant. CABS is an airframe-mounted system similar to that used by the automotive industry. The multiple bag design is cockpit specific and the sensor is tuned to the airframe crash characteristics. The combined forward and vertical velocity conditions that were selected for both tests are considered moderately severe and represent a high percentage of survivable crashes. The impact tests were conducted on both soft soil and concrete. A photograph is shown in Figure 12 of one of the full-scale crash tests of the AH-1S helicopter with IBAHRS and CABS deployed. In both tests the IBAHRS and CABS were fully deployed at the proper time to provide their maximum protection capabilities. This program demonstrated that these systems have the potential to reduce the number of injuries and fatalities resulting from occupant contact with interior cockpit structures in a crash. Currently, the U.S. Army has ordered retrofit of UH-60 Black Hawk and OH-58 Kiowa Warrior helicopters to be outfitted with CABS based on the results of this successful test program.

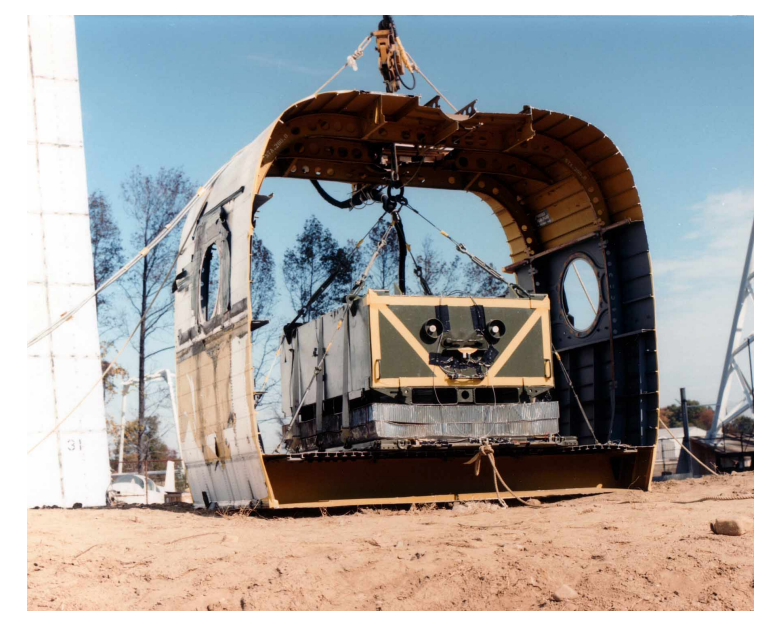

(a) Pre-test photograph

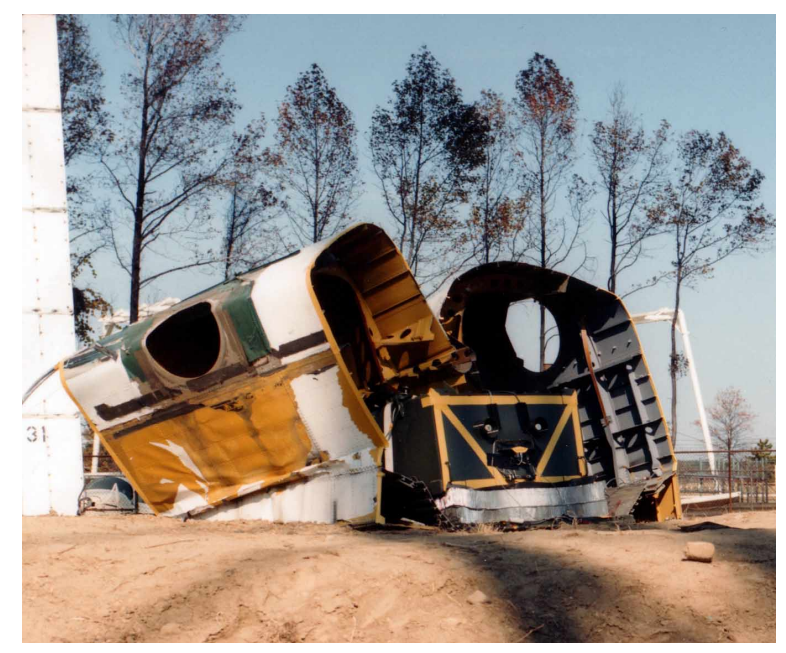

(b) Post-test photograph.

Figure 11. Pre- and post-test photographs of a CH-47 helicopter section with the ITOC container.

Qualification Tests of an External Fuel System for the UH1 Huey Helicopter

In 1994, three UH-1 Huey helicopters were crash tested at the IDRF to qualify an External Fuel System (EFS) proposed for National Guard helicopters. Pre-test photographs of one of the UH-1 helicopters outfitted with external fuel tanks are shown in Figure 13. The external fuel system included left and right conformal tanks each with a capacity of approximately 75 gallons. One right and two left external tanks were available for 
the qualification program. An additional right tank that was used previously in ballistic test evaluation was repaired and used in the crashworthiness qualification. These external tanks attach to hard points on the fuselage subfloor sides. All tests were conducted with a nominal $9,000 \mathrm{lb}$. gross weight for the helicopters including the EFS, simulated fuel, attached swing fixture, and instrumentation. The tests were conducted by swinging the aircraft pendulum-style into the ground with combined impact velocities from 32- to 51-fps and with a 51.3-degree flight path, a 10-degree nose-up pitch, and 0-degree yaw. The helicopters were rolled 15-degrees to the left for the first two tests and 26-degrees to the right for the third test. The pass/fail criteria for these tests were based on the nature and amount of leakage from the tanks. Water was used as a fuel substitute. Because of the higher specific gravity of water compared to aviation fuel, the main and external fuel tanks were filled to $80 \%$ of their capacity to represent the weight of the aviation fuel. Red and green water-soluble dyes were used in the EFS tanks to identify the source of any leakage that might occur and to distinguish leakage in the EFS from leakage in the main fuel system where clear water was used. As a result of the successful qualification tests performed at the IDRF, the EFS was approved for use on National Guard helicopters as a means of extending their range and/or increasing payload.

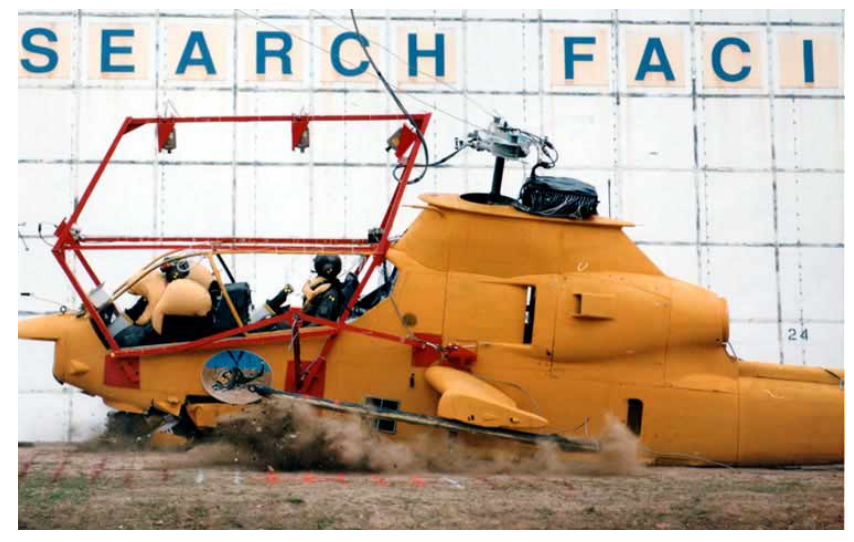

Figure 12. Photograph of a crash test of the AH-1S helicopter with crew restraint systems.

\section{Crash Testing of the F-111 Crew Escape Module}

Beginning in the 1980's and continuing through the mid1990's, impact tests of the F-111 crew escape module were performed at the IDRF in support of the U.S. Air Force. In the event of an emergency, the F-111 crew escape module is separated from the aircraft and the module descends to Earth with the aid of a parachute. However, even with the parachute, the Air Force reported that the impact of the crew module with the ground resulted in a high percentage of injuries and some fatalities. Consequently, an external airbag energy attenuation system was designed for the crew escape module. The airbag was located on the flat underside of the module and contained blowout plugs that were designed to tailor the amount of energy absorbed. During the 15-year period of time, over 60 impact tests were performed of the F-111 crew module with different airbag designs. The objectives of the tests were to: (1) determine the impact loads generated by the airbag system and subsequently transmitted to the occupants during impact; (2) to characterize the stability of the module under various impact attitudes; and, (3) to assess design changes to the airbag attenuation system. A photograph of an F-111 crew module with airbag inflated prior to an impact test at the IDRF is shown in Figure 14. Note the complex cable system used to obtain the appropriate impact attitude for the test in the photograph. Many of the tests were conducted onto a soft soil surface under a variety of roll, pitch, and yaw angles to represent the range of impact attitudes possible with a parachute landing. A series of photographs taken during one of these tests is shown in Figure 15. As stated in Reference 9, "As a result of the data provided to the Air Force, load attenuating crew seats were included in the F-111 and airbag and blowout plug design changes were made to the original airbags. Various changes to the module led to the design of a new airbag system, which was tested for qualification on the F-111 in the final series of tests prior to retirement of the F-111 fleet."

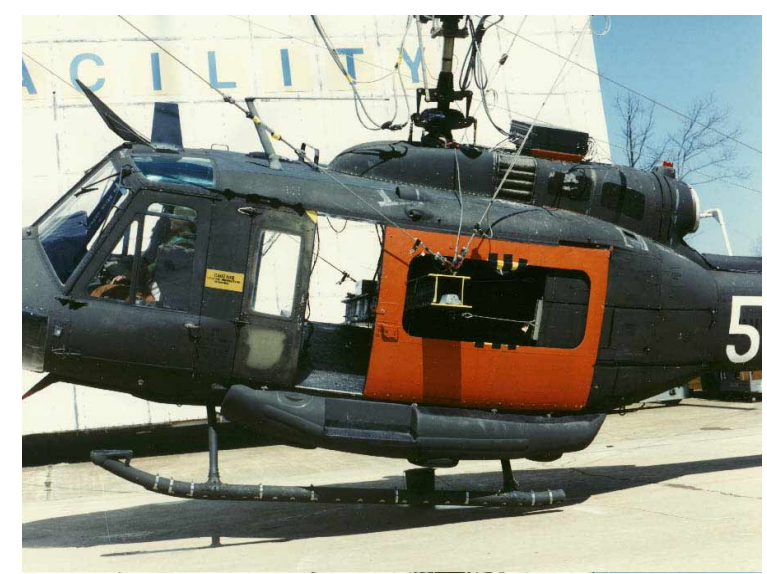

(a) Side view showing EFS.

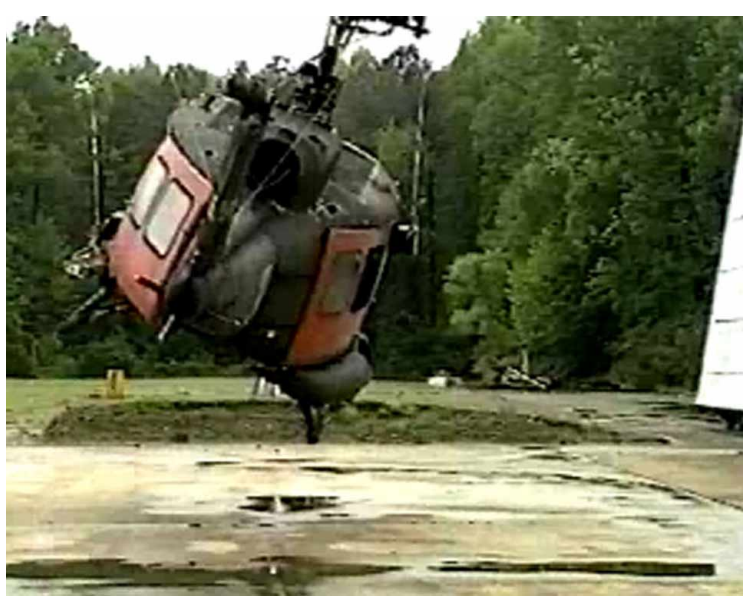

(b) Rear view showing rolled impact attitude.

Figure 13. Pre-test photographs of a UH-1 Huey helicopter with external fuel tank. 


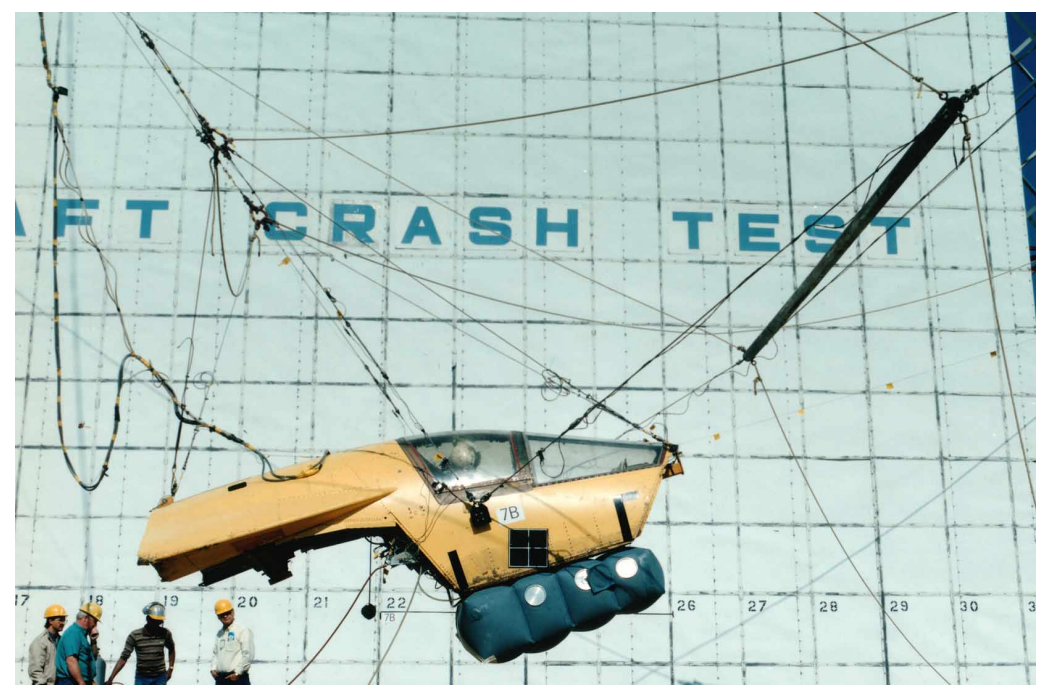

Figure 14. Pre-test photograph of the F-111 crew escape module with airbag attenuation system.
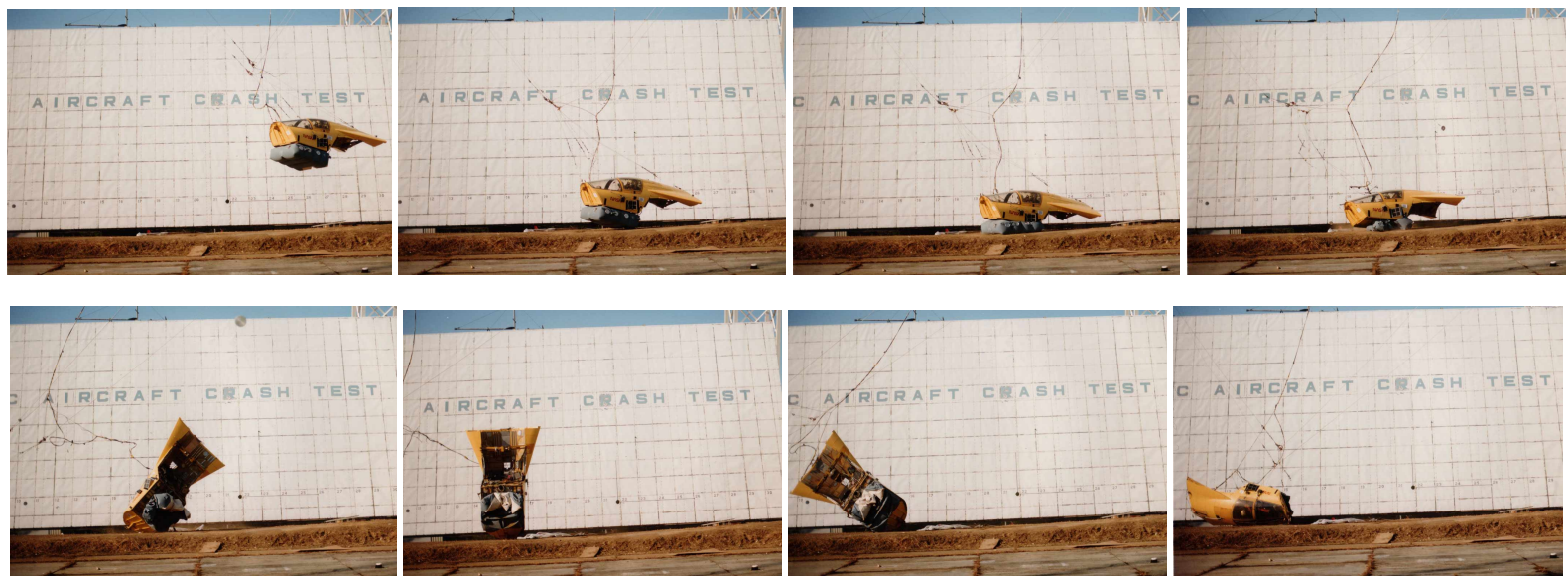

Figure 15. Series of photographs of an F-111 crew module impact test.

\section{Vertical Drop Testing of Fuel Bladder Systems}

In 1994, vertical drop tests of helicopter fuel bladders were performed using the 70-ft. drop tower at the IDRF to study the effect of different constraints on the hydrodynamic pressure-time pulses that occur during crash impact. Five tests were performed through a Cooperative Research and Development Agreement with McDonnell Douglas Helicopter Company. These tests included the fuel bladder alone and a combination of rigid and flexible side and bottom constraints surrounding the bladder. Depending on its location, the high pressure pulse in the fuel bladder generated during a crash impact may result in a catastrophic failure of primary structures and/or a reduction of the energy absorbing capabilities of the airframe. In addition, the high internal hydrodynamic pressures are likely to result in fuel leakage and post-crash fire hazard [18]. A photograph of the fuel bladder rebounding during one of the drop tests is shown in Figure 16. Results of the testing showed that placing energy absorbing materials under the bladder is the most effective means of reducing peak pressure loads due to the initial shock wave. Also, an analysis methodology based on the nonlinear finite element program DYNA3D [19] was validated for design and integration of crashworthy helicopter fuel tanks.

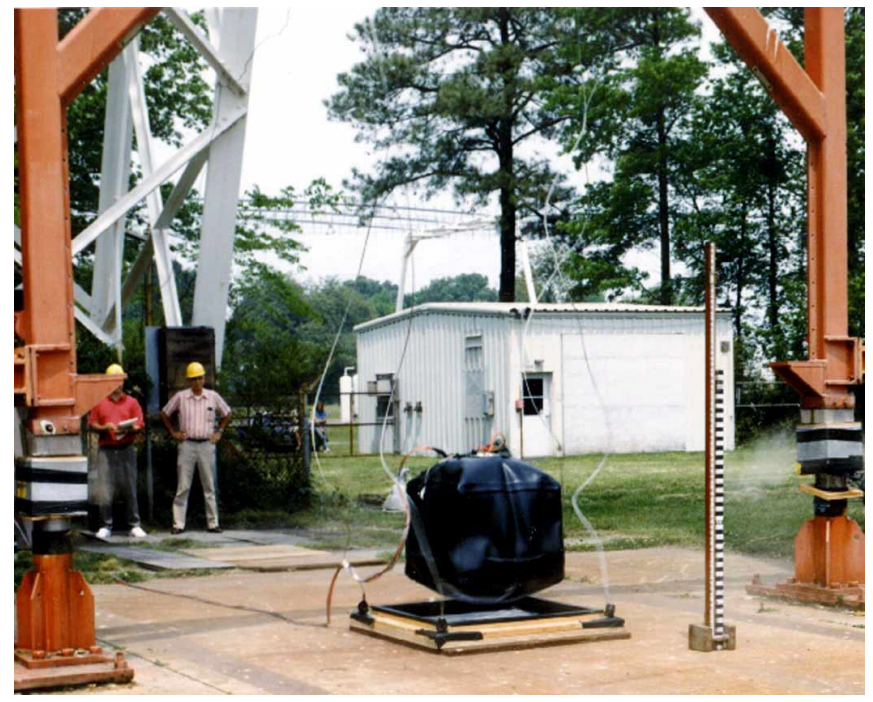

Figure 16. Photograph of a fuel bladder drop test. 


\section{Pallet Testing for Remote-Controlled Vehicle}

In 1996, tests were performed at the IDRF to demonstrate an energy absorbing pallet system for an airdrop of an unmanned robotic vehicle in support of the Remote Warfare Operations program. The U.S. Army Early Entry Lethality and Survivability Battlelab, located at Ft. Monroe, VA, sponsored the tests. The pallet system was designed to minimize the impact loads to the robot using the Guided Precision Air Delivery System (GPADS). The airdrop system must also allow the robot to derig itself, drive off the pallet, and perform its mission with only remote human control. In addition, the pallet must be constructed using materials readily available to a soldier in the field. To accomplish these goals, an energy absorbing pallet concept was designed. Five impact tests were conducted at typical airdrop impact velocities, and mechanical and pyro-technique derigging systems were developed by IDRF personnel [20]. A photograph of one of the pallet impact tests with the robot attached is shown in Figure 17. This program was extremely successful in that a simple and effective pallet was designed that limited the accelerations transmitted to the robot to approximately $12-\mathrm{g}$ for flat, rolled, and pitched impact attitudes. The robot was capable of derigging itself and driving safely off the pallet.

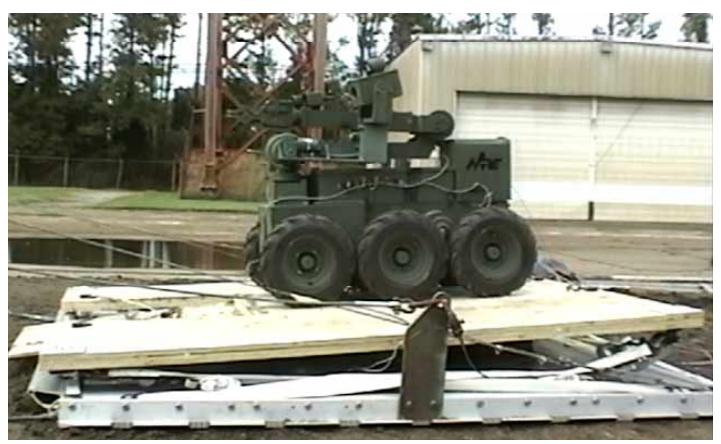

Figure 17. Photograph of an impact test of an energyabsorbing pallet with robot.

\section{Full-Scale Crash Test of the Sikorsky ACAP Helicop- ter (Flight Test Article)}

A full-scale crash test of the Sikorsky ACAP helicopter was performed at the IDRF in 1999. The main purpose of the test was to obtain experimental data for validation of a finite element crash simulation. The helicopter was the flight test article built by Sikorsky Aircraft under sponsorship by the U.S. Army during the ACAP. The helicopter was constructed primarily of advanced composite materials and was designed to meet the Army's stringent MILSTD-1290A crashworthiness criteria. For the crash test, the aircraft was outfitted with two crew and two troop seats and four instrumented anthropomorphic dummies. The test was performed at 38-fps vertical and 32.5-fps horizontal velocity onto a rigid impact surface [21]. Approximately 120 channels of dynamic data were collected. Photographs of the helicopter taken just prior to and after impact are shown in Figure 18.
In addition to obtaining structural crash data for validating the nonlinear transient dynamic computer simulation, several ancillary experiments were included. A programmable electronic crash sensor unit (ECSU) was mounted on the cabin floor near the troop seats. The sensor was typical of the kind that might be used to inflate an airbag. During the test, the ECSU operated successfully and was very helpful in obtaining time synchronization between the exterior and interior cameras. In addition, the left and right fuel tanks were instrumented with two transducers each to measure the hydrodynamic pressure pulse during impact. The pilot and copilot dummies were seated in two military-qualified load-limiting seats from two different vendors. The troop dummies were seated in ceiling-suspended troop seats, each with two wire-bender energy absorbers that were mounted in the rear cabin area of the helicopter. The detailed seat and occupant response data obtained from the crash test were evaluated and the occupant data were correlated with injury prediction models [22].

This project represented the first attempt to develop a full three-dimensional finite element crash model of a helicopter, to execute an explicit transient dynamic simulation representing the structural impact, and to perform test-analysis correlation to validate the simulation [23]. The finite element model is depicted in Figure 19. This project resulted in the successful demonstration of the capabilities of commercial crash simulation codes for predicting the dynamic structural response of the airframe, thus building confidence in the application of these codes as crashworthy design and qualification tools.

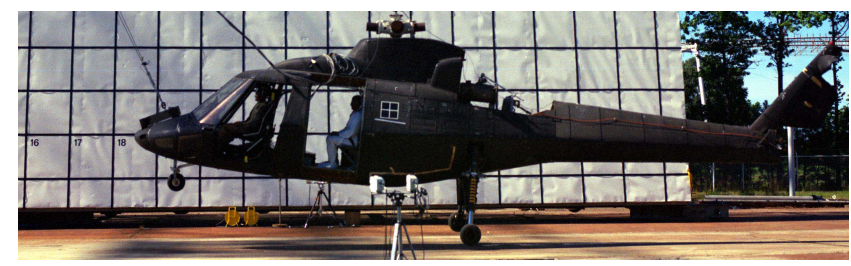

(a) Photograph of the ACAP helicopter at impact.

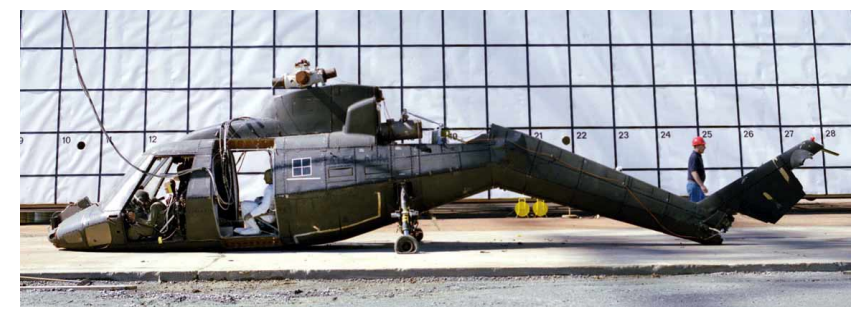

(b) Post-test photograph.

Figure 18. Photographs of the Sikorsky ACAP helicopter.

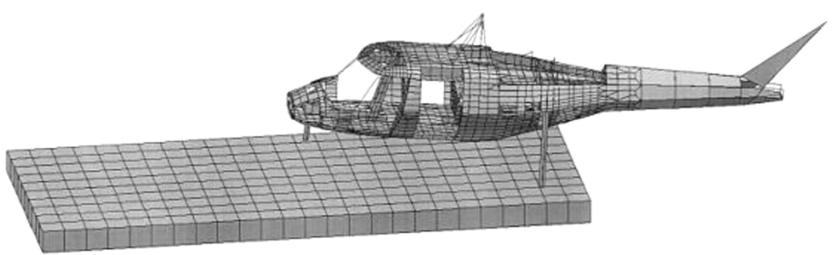

Figure 19. Finite element model of the ACAP helicopter. 


\section{Qualification Tests of an External Fuel Tank for the UH-60 Black Hawk Helicopter}

The U.S. Army has retrofitted its entire helicopter fleet with crashworthy internal fuel systems to greatly reduce post-crash fire hazards. It also has a large inventory of 230 -gallon external fuel tanks that were originally designed for ferry missions only and which could be jettisoned. These external fuel tanks were not designed to the same crash resistance standard as the internal fuel tanks. Because of the increased use of these tanks in low-level flying missions where the tanks cannot be safely jettisoned during a mishap, the external tanks need to be as crash resistant as the on-board tanks. In December of 1999, the U.S. Army AATD sponsored a full-scale crash test of a UH-60 Black Hawk helicopter at the IDRF to verify the performance of two modified 230-gallon external fuel tanks [24, 25]. The Black Hawk airframe used in this test was already crash damaged and did not have a tail cone. The external tanks can be mounted on the External Stores Support System (ESSS) utilized on the UH60 Back Hawk, the AH-64 Apache, and the RAH-66 Comanche helicopters. The external fuel tanks were attached to the left and right outboard positions of the ESSS wings mounted on the helicopter. The tanks were filled approximately $80 \%$ full of water to simulate the full-tank weight of JP-8 fuel. The helicopter was impacted with vertical and forward velocities of 42- and 50-fps, respectively onto concrete. The attitude of the helicopter at impact was 6-degrees nose-up pitch, 17-degrees left roll, and 17-degrees right yaw. These impact conditions are much more severe than those specified in MIL-STD-1290A for occupant survivability. Photographs depicting the fullscale crash test of the UH-60 Black Hawk helicopter are shown in Figure 20. The results of the test indicate that both external fuel tanks survived the severe impact condition with only minor leakage, even though they experienced a large transient pulse during the impact test. These findings validated the crash resistance of the modified fuel tank design allowing the Army to more fully utilize these ESSS-mounted tanks to provide extended range for helicopter missions.

\section{STATUS OF THE IDRF}

The final DOD-sponsored full-scale crash test was performed at the IDRF in 1999. However, full-scale crash tests and vertical drop tests continued to be performed at the facility through 2003, including a vertical drop test of a fuselage section of an F-28 commuter-class aircraft, as well as a full-scale crash test of a modified Lancair GA aircraft. A large portion of this research was performed under sponsorship of the Accident Mitigation Element of the NASA Aviation Safety Program [26]. The Accident Mitigation Element was comprised of two parts: aircraft crash safety and crash-resistant fuel systems. On October 31,2002 , the funding for the crash safety portion (only) of the Accident Mitigation Element was cancelled. Subsequently, the IDRF gantry was officially closed by NASA
Langley on September 30, 2003, and plans are underway to demolish the facility in 2007.

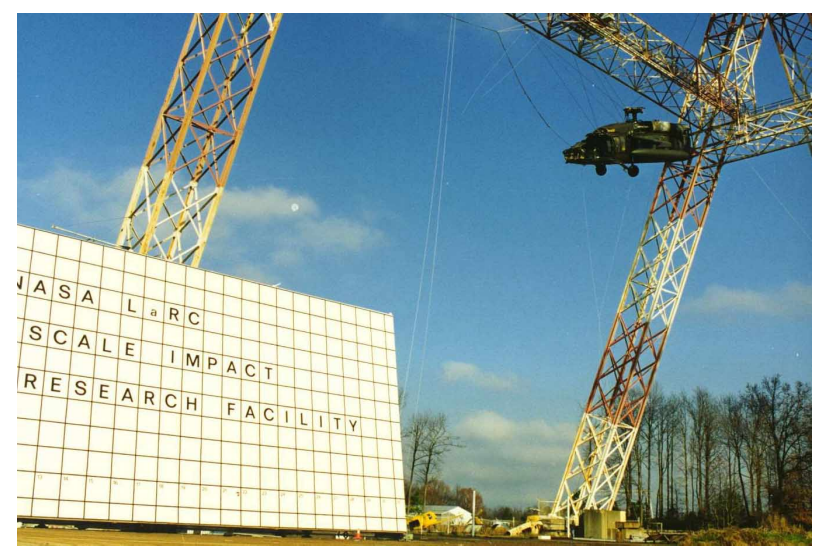

(a) Photograph showing the test article in the release position.

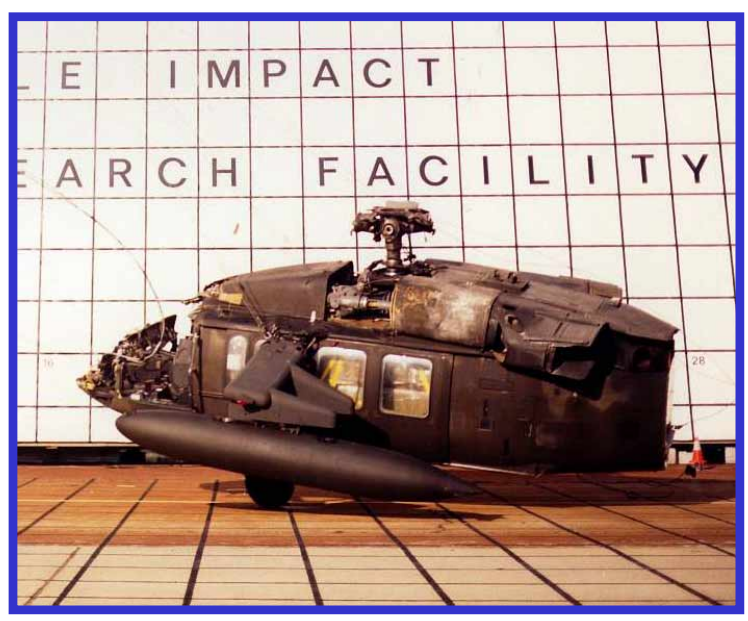

(b) Photograph during impact.

Figure 20. Photographs of the UH-60 Black Hawk helicopter full-scale crash test.

\section{CONCLUDING REMARKS}

The Impact Dynamics Research Facility (IDRF) located at NASA Langley Research Center is a 240-ft.-high gantry structure that was originally built in the early 1960's for use as a Lunar Landing Research Facility. As such, the facility was used to simulate the reduced gravitational environment of the Moon, allowing the Apollo astronauts to practice lunar landings under realistic conditions. The IDRF was designated a National Historic Landmark based on its significant contributions to the Apollo Moon Landing Program. In the early 1970's the facility was converted into its current configuration as a full-scale crash test facility for light aircraft and rotorcraft. Since that time, the IDRF has been used to perform a wide variety of impact tests on full-scale aircraft and airframe components in support of the General Aviation (GA) aircraft industry, the U.S. Department of Defense, the rotorcraft industry, and the NASA Space program. The objectives of this paper are to describe the IDRF facility and its capabilities for conducting 
structural impact testing, and to summarize the impact tests performed in support of the DOD.

The full-scale crash tests conducted at the IDRF provided the DOD with valuable and unique data, which improved the crash safety of many aircraft. These tests cover a time period of roughly 2-1/2 decades, beginning in 1975 with the crash test of a $\mathrm{CH}-47$ Chinook helicopter, and ending in 1999 with a crash test of a UH-60 Black Hawk helicopter to qualify an external fuel system. Some of the most significant contributions made through the DODsponsored test programs are qualification of a passive Wire Strike Protection System (WSPS) for different Army helicopters; evaluation of the crashworthy performance of prototype composite airframes, load-limiting seats, and occupant restraint systems including onboard airbag systems; and, qualification of two external fuel systems for four Army helicopters.

\section{ACKNOWLEDGEMENTS}

The authors would like to express their appreciation for the contributions of Mr. Leroy Burrows, formerly of the U.S. Army AATD, who provided data regarding some of the early military test programs.

\section{REFERENCES}

1. O'Bryan, T. C., and Hewes, D. E., "Operational Features of the Langley Lunar Landing Research Facility," NASA TN D-3828, February 1967.

2. O'Bryan, T. C., "Flight Tests of a Manned RocketPowered Vehicle Utilizing the Langley Lunar Landing Research Facility," Proceedings of the AIAA Guidance and Control Specialists Conference, Seattle, Washington, August 15-17, 1966.

3. Vaughan, V. L., Jr., Alfaro-Bou, E., "Impact Dynamics Research Facility for Full-Scale Aircraft Crash Testing," NASA TN D-8179, April 1976.

4. Jackson, K. E., and Fasanella, E. L., "A Survey of Research Performed at NASA Langley Research Center's Impact Dynamics Research Facility, AIAA-2003-1896, Proceedings of the $44^{\text {th }}$ AIAA Structures, Structural Dynamics, and Materials Conference, Norfolk, VA, April 7$10,2003$.

5. Boitnott, R. L., and Jones, L. E., "NASA-Langley Research Center's Impact Dynamics Research Facility FullScale Crash Test Procedures," Proceedings of the Third International KRASH User's Conference, Phoenix, AZ, January 7-10, 2001.

6. Singley, G. T., III, "Full-Scale Crash Testing of a CH47C Helicopter," Proceedings of the $32^{\text {nd }}$ Annual National V/STOL Forum of the American Helicopter Society, Washington, D. C., May 1976.
7. Burrows, L., Lane, R., and McElhenney, J., "CH-47 Crash Test (T-40) Structural, Cargo Restraint, and Aircrew Inflatable Restraint Experiments," USARTL-TR-78-22, April 1978.

8. Gamon, M. A., "KRASH User's Manual: Thoery Volume I," FAA-RD-77-1891, Lockheed-California Company, September 1979.

9. Chambers, J. R., "Partners in Freedom: Contributions of the Langley Research Center to U.S. Military Aircraft of the 1990's," NASA SP-2000-4519, Monographs in Aerospace History Number 19, 2000.

10. Burrows, L. T., "Investigation of Helicopter Wire Strike Protection Concepts," USAAVRADCOM-TM-80-D-7, U.S. Army Applied Technology Laboratory, Ft. Eustis, VA, June 1980.

11. Burrows, L. T., "Verification Testing of a UH-1 Wire Strike Protection System (WSPS)," USAAVRADCOM-TR-82D-35, U.S. Army Applied Technology Laboratory, Ft. Eustis, VA, November 1982.

12. Burrows, L. T., "Verification Testing of an AH-1S Wire Strike Protection System (WSPS)," USAAVRADCOM-TR-82D-36, U.S. Army Applied Technology Laboratory, Ft. Eustis, VA, December 1982.

13. Perschbacher, J.P., Clarke, C., Furnes, K., and Carnell, B., "Advanced Composite Airframe Program (ACAP) Militarization Test and Evaluation (MT\&E) Volume V- Airframe Drop Test," USAATCOM TR 88-D-22E, March 1996.

14. Thomson, D. T., and Clarke, C.W., "Advanced Composite Airframe Program (ACAP) Militarization Test and Evaluation (MT\&E) Volume I- Landing Gear Drop Test," USAAVSCOM TR-88-D-22A, August 1989.

15. Cronkhite, J. D., and Mazza, L. T., "Bell ACAP Full-Scale Aircraft Crash Test and KRASH Correlation," Proceedings of the 44th Annual Forum of the American Helicopter Society, Washington D.C., June 16-18, 1988.

16. Fasanella, E. L., Jones, L. E., and Carden. H. D., "Interim Transportation Overpack Container (ITOC) Experiments and Analysis," NASA TM-101510, October 1988.

17. Pilati, B. P., Jones, L. E., "Active Crew Restraint Demonstration," Proceedings of the American Helicopter Society 50th Annual Forum and Technology Display, Washington, DC, May 11-13, 1994.

18. Boitnott, R. L., Bolukbasi, A. O., and Kellas, S., "Helicopter Fuel Bladder Drop Tests and Analyses," Proceedings of the $50^{\text {th }}$ American Helicopter Society Forum, Washington DC, May 1994.

19. Whirley, R. G., and Engelmann, B. E., DYNA3D, A Nonlinear, Explicit, Three-Dimensional Finite element Code 
for Solid and Structural Mechanics," Lawrence Livermore National Laboratory, Livermore, CA, November 1993.

20. Boitnott, R. L., and Pritchard, J. I., "Design and Evaluation of an Energy Absorbing Pallet for Remote Warfare Operations," VTC Internal Report, VTC NR 9701, February 1997.

21. Boitnott, R. L.; Jackson, K. E.; Fasanella, E. L.; Kellas, S.: "Full-Scale Crash Test of the Sikorsky Advanced Composite Airframe Program Helicopter," Proceedings of the American Helicopter Society Forum 56, Virginia Beach, VA, May 2-4, 2000.

22. Jackson, K. E., Fasanella, E. L., Boitnott, R. L., McEntire, J., and Lewis, A., "Occupant Responses in a Full-Scale Crash Test of the Sikorsky ACAP Helicopter," Proceedings of the AHS Forum 58, Montreal, Canada, June 11-13, 2002.

23. Jackson, K. E. Fasanella, E. L., Boitnott, R. L., and Lyle, K. H., "Full-Scale Crash Test and Finite Element Simulation of a Composite Prototype Helicopter," NASA/TP-2003-212641, ARL-TR-2824, August 2003.

24. Boitnott, R. L., "Crash Verification Test of Modified External Fuel Tanks, VTD Internal Report, VTD NR 0003, June 2000.

25. Robertson, H., Banks, F., and Nolan, K., "Development and Testing of a Crashworthy External Fuel System for the UH-60, AH-64, and RAH-66 Helicopters," Proceedings of the $59^{\text {th }}$ AHS Forum, Phoenix, AZ, May 6-8, 2003.

26. Jones, L. E., "Overview of the NASA Systems Approach to Crashworthiness Program," Proceedings of the $58^{\text {th }}$ Annual American Helicopter Society Forum, Montreal, Canada, June 13-15, 2002. 